\title{
Discrete fracture network based approaches to assessing inter-ramp design
}

\author{
M Valerio Golder, Canada \\ S Rogers Golder, Canada \\ KP Lawrence Golder, USA \\ KM Moffitt Golder, USA \\ B Rysdahl Rio Tinto Kennecott, USA \\ M Gaida Rio Tinto Kennecott, USA
}

\begin{abstract}
At the inter-ramp scale, critical failure mechanisms in slopes consisting of moderately to highly fractured competent rock masses commonly involve a combination of failure along discontinuities and through the rock mass. While several analysis methods are available for assessing inter-ramp slope stability (such as kinematic, limit equilibrium, and elastic/plastic modelling), most have limitations when applied to failure mechanisms involving structure and rock mass. For example, simple kinematic methods are effective for assessing structurally controlled failure mechanisms, but at the inter-ramp scale, more sophisticated approaches are required to evaluate potential step-path failures that involve shearing through a combination of structure and rock mass. For inter-ramp stability analyses where failure through rock mass is expected, limit equilibrium methods and continuum stress-displacement modelling (e.g. finite element and finite difference tools) are commonly used. Structural sets that provide preferential planes of weakness within the rock mass can be incorporated into these types of analyses as ubiquitous joints or anisotropic strength orientations. However, these modelling techniques are not practical for evaluating variations in orientation, spacing, and persistence of several structural sets or for evaluating the impact of multiple structural sets in three dimensions.

This paper presents alternative approaches for inter-ramp slope stability analysis and design using discrete fracture network (DFN) based methods. DFN models provide synthetic realisations of fracture networks within pit walls that can be used to: 1) estimate rock mass bridges using search algorithms that identify failure pathways of least resistance through networks with unconstrained fracture orientation, spacing, or length variations; and 2) identify fully formed or nearly fully formed three-dimensional (3D) rock blocks and evaluate their stability. This paper describes a method for rock mass bridge characterisation using stochastic DFNs and how this can be incorporated into kinematic inter-ramp stability analyses by adjusting discontinuity strengths. This paper also describes how the stability of rock blocks identified in DFN models can be assessed using a custom 3D stress-based limit equilibrium tool that can approximate composite structural and rock mass block boundaries.

A case study is presented to illustrate how these DFN-based approaches were applied to develop inter-ramp slope angle recommendations for a pushback design at the Bingham Canyon mine. The analysis methods described in this paper provide practical tools for efficiently evaluating complex failure mechanisms and informing the choice of design inter-ramp angles.
\end{abstract}

Keywords: inter-ramp slope stability, DFN, rock mass bridges, kinematic analysis, 3D limit equilibrium

\section{Introduction}

Open pit slope design typically involves stability analysis at the bench, inter-ramp, and overall slope scales. At the local bench-scale, failure mechanisms tend to be structurally controlled. However, at the inter-ramp 
and overall slope scales, analysis must also consider the potential for composite failure mechanisms to develop that involve shearing through rock mass and along discontinuities. These complex mechanisms are typically assessed through limit equilibrium (LE) methods or more advanced numerical analyses including continuum- and discontinuum-based models. However, assessing complex fracture networks using these types of tools can be computationally challenging and often impractical.

This paper describes some of the common approaches to inter-ramp slope design and highlights the main limitations of these methods when applied to analysis of composite rock mass and structural instability mechanisms. Two alternative approaches that integrate different methods and use discrete fracture network (DFN) techniques are presented. Examples are provided to illustrate how these alternative approaches were used to develop inter-ramp angle (IRA) recommendations for a pushback design at the Rio Tinto Kennecott Bingham Canyon mine.

\section{$2 \quad$ Existing methods for inter-ramp slope design}

Common approaches to inter-ramp slope design include kinematic analysis, LE methods, and numerical analyses such as finite element and distinct element methods. The type of analysis selected for inter-ramp slope design depends mainly on the expected failure mechanism, the data available for developing input parameters, and the level of design required (e.g. pre-feasibility, feasibility, or detailed design).

Kinematic analysis is used to assess the potential for structurally controlled failures (e.g. plane, wedge, and toppling) to occur. This type of analysis is typically applied to bench-scale design, as simple structurally controlled failure mechanisms are less common at the inter-ramp and overall slope scales. However, kinematic methods are also used for inter-ramp slope design in cases where persistent structures, such as continuous faults, exist and have the potential to form large-scale blocks or wedges. For assessing more complex failure mechanisms that involve rock mass failure, other types of analysis, including LE methods and numerical modelling, are typically used. Each of these typically involve significant simplification of the real rock mass complexity and response.

LE analysis is widely used for inter-ramp slope design as the method is relatively simple and fast, and it can be used to assess potential failure mechanisms involving rock mass and structures using commercially available software. Many of the LE-based programs available provide tools for simulating anisotropic strength within the rock mass, which allows structural sets that represent preferential planes of weakness to be incorporated implicitly into the models. However, these tools are not adequate for assessing variations in the spacing, persistence, and orientation of several structural sets.

More advanced numerical methods provide sophisticated techniques for assessing inter-ramp slope stability, but these types of analyses are typically reserved for the later design stages (e.g. feasibility and detailed design) due to their complexity and additional data requirements for input parameter definition and calibration. In continuum analyses, one structural set within the rock mass can be simulated using ubiquitous joint models. However, as discussed by Carvalho et al. (2019), ubiquitous joints should be used with caution since they may fail to capture the correct deformation behaviour, particularly in models that contain large continuous structures, because the element-based constitutive model fails to propagate the discontinuity across element boundaries in a continuum. An alternative to using ubiquitous joint models is to define the fracture network explicitly using joints or interfaces in continuum- or discontinuum-based models. However, due to the high computational demands of modelling discrete fractures, typically only a small percentage of the structure can be included in the analysis, and it is not feasible to conduct multiple simulations to assess the impact of variations in fracture orientation, spacing, and persistence.

DFN methods that explicitly incorporate large-scale deterministic structures (e.g. faults) and smaller scale stochastic features (faults and, where necessary, joints) are more adept at conducting probabilistic stability analysis of daylighting wedges and blocks (Merrien-Soukatchoff et al. 2012; Rogers et al. 2006, 2018a). However, at the inter-ramp scale, analysis of more complex failure mechanisms that involve both shearing through the rock mass and subsequent kinematic sliding presents a challenge because DFN models cannot directly simulate the rock mass shear component of failure. 
There is a clear need for an alternative approach that can address the structural complexity that is often present in large open pits and can also rapidly evaluate a large number of potential instabilities comprising both rock mass and structural failure.

\section{DFN-based approaches to inter-ramp slope design}

DFN models provide a statistical representation of the rock mass fracture system that is based on fundamental information of observed fractures, including their size (persistence), orientation, and intensity. Large-scale deterministic structures available as wireframe surfaces in geological models can be explicitly included within the DFN model as well. Smaller faults and even joints (where appropriate) are stochastically generated from tabulated borehole and mapping data. This DFN approach is well described elsewhere (e.g. Rogers et al. 2009). This section provides two examples of how DFN-based approaches combined with more conventional slope stability analysis methods can be used for inter-ramp slope design.

The first approach (Section 3.1) uses DFN-based rock mass bridge characterisation in conjunction with conventional kinematic methods to assess inter-ramp slope stability. This approach involves performing probabilistic kinematic analyses that incorporate composite discontinuity and rock mass strengths to account for limited persistence of structures. The second approach (Section 3.2) uses DFN models to identify fully enclosed three-dimensional (3D) blocks of rock that intersect a pit surface, and then assesses the stability of the blocks using a 3D stress-based LE tool developed by Golder Associates (Golder) that is capable of efficiently analysing many thousands of blocks. With both methods, the results can be aggregated to allow block stability statistics to be presented as a function of inter-ramp slope angle and azimuth.

\subsection{Kinematic analysis with DFN-based rock mass bridge characterisation}

Conventional kinematic analysis evaluates the sliding potential of wedges on joints, typically at the bench-scale. At the inter-ramp scale in high slopes, critical failure surfaces typically form as a composite pathway that involves plane shear along discontinuities and failure through zones of rock mass, referred to as 'rock mass bridges' (Figure 1). The presence of rock mass bridges can substantially improve the stability of a slope by imparting a higher overall shear/tensile strength to step-path failure surfaces.

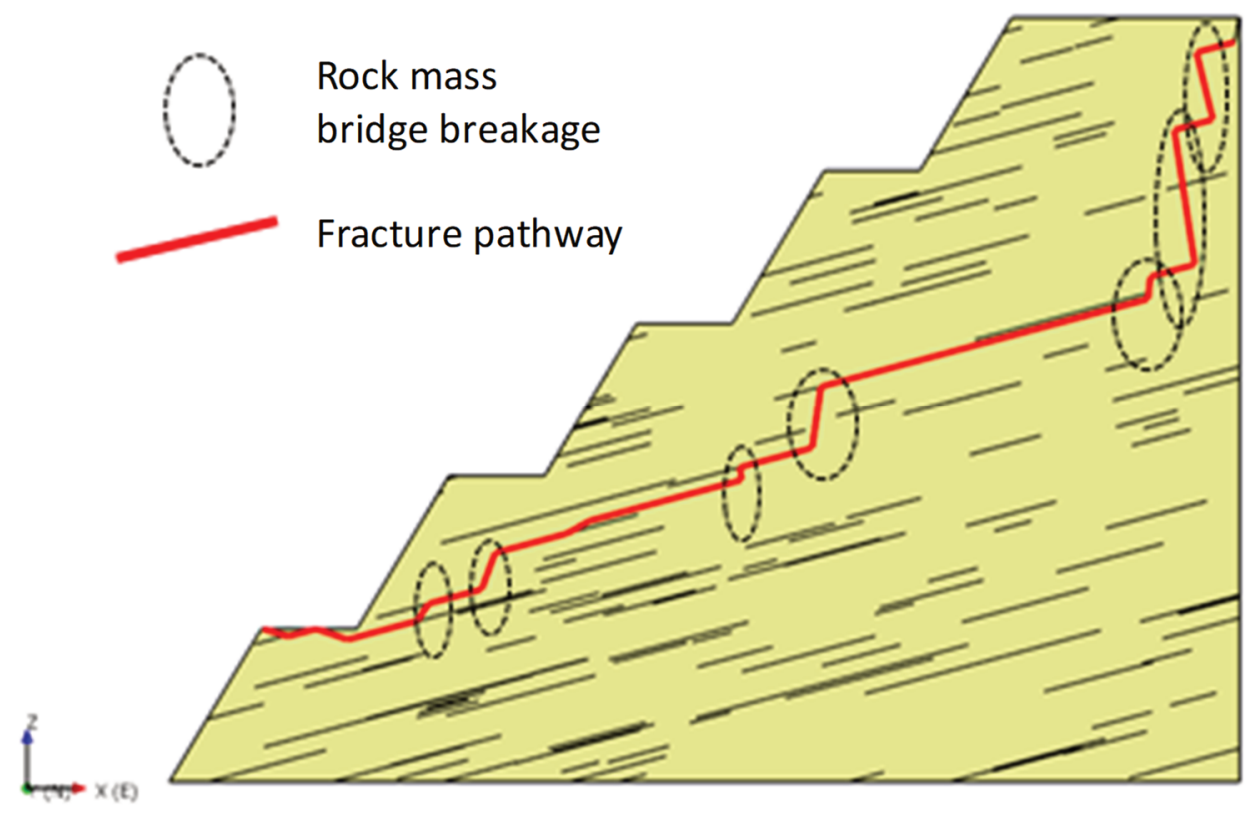

Figure 1 Failure path showing fracture pathways and rock mass bridge breakage

The relative proportions of rock mass and discontinuities along a failure path that exploits dominant fracture trends can be determined using DFN models (Dershowitz et al. 2017; Rogers et al. 2018b). These proportions can be used to calculate a rock mass bridge percentage for that failure path. 
Multiple realisations of the DFN model can be generated and used to develop a statistical distribution of rock mass bridge percentage. Based on that statistical distribution, a design rock mass bridge percentage can be determined and used to define composite strength parameters (cohesion and friction angle) for the sliding surfaces that combine discontinuity and rock mass strengths. These composite strengths can then be used as input to kinematic stability analyses. Assuming that the rock mass bridges fail in pure shear is a necessary simplification. In reality, rock mass bridge failure will probably occur in shear and tension on a stepped path. The impact of this assumption on the overall rock mass bridge sheared length, and thus its strength, is not believed to be significant and will be evaluated in future studies.

The kinematic analysis with rock mass bridge characterisation approach was applied to a geotechnical design study for a pushback at Rio Tinto Kennecott's Bingham Canyon mine with the workflow summarised in Figure 2.

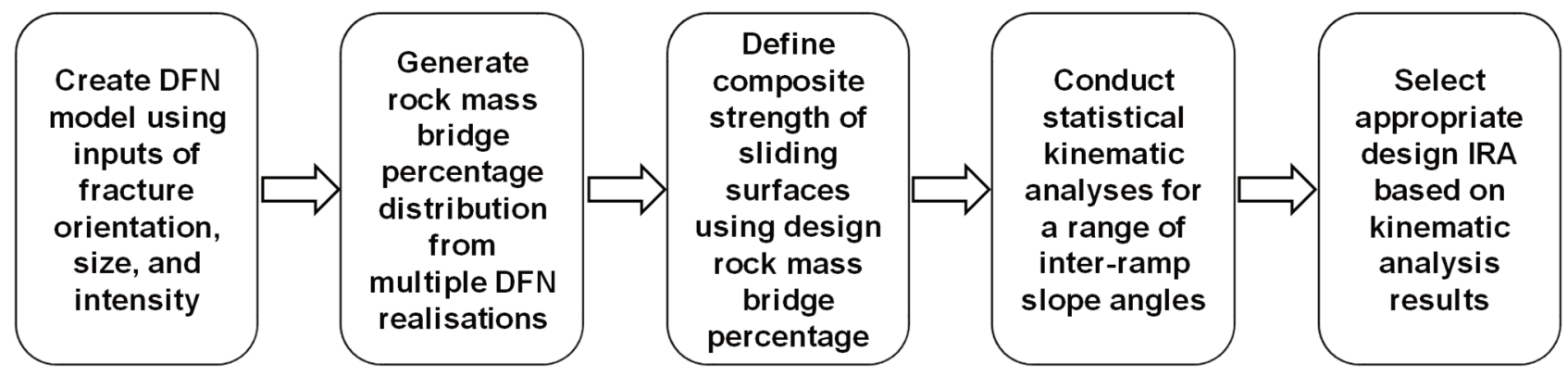

Figure 2 Workflow for incorporating rock mass bridges into inter-ramp kinematic stability analysis

The process is illustrated for a specific region of the mine where the critical inter-ramp mechanism has been identified, based on the available structural data, as planar sliding along faults and persistent joints. The height of the region of the slope is approximately $200 \mathrm{~m}$ (14 benches) and the rock mass consists mainly of medium strong to strong, fair quality monzonite. Although the case study discussed in the following sections considers a planar failure mechanism, this same approach has been applied to wedge kinematic analysis by determining rock mass bridge percentage and composite strength parameters for each of the critical structural sets defining the wedges.

\subsubsection{DFN generation}

DFN models were constructed using the software FracMan ${ }^{\circledR}$ (Golder 2019). Fracture orientations determined from analysis of geotechnical core logging, acoustic televiewer, and pit wall mapping data were input into the DFN model using the 'bootstrapping' technique. Bootstrapping is a statistical method based on multiple random sampling with replacement from an original sample to create a pseudo-replicate sample of fracture orientations (Efron 1979). Fracture frequency (P10) values were determined from geotechnical core logging and acoustic televiewer data and converted to a volumetric fracture intensity property, P32 (i.e. fracture surface area per unit volume), using the method developed by Chiles et al. (2008). The intensity system (Pij) is defined in Dershowitz \& Herda (1992). Fracture size distribution was determined from pit wall mapping data, and drone-acquired photogrammetry data and were found to be represented by a power law relationship, which allows generation of fractures over a wide range of lengths (Cladouhos \& Marrett 1996).

The workflow to develop and filter DFN models for the purpose of rock mass bridge characterisation is illustrated in Figure 3. The first step is to setup a 3D box and define a two-dimensional (2D) plane through the centre of the box, with the plane oriented parallel to the mean dip and dip direction of the critical structural set. Next, the DFN model is stochastically generated in the 3D box using the fracture size, intensity, and orientation inputs determined from field data. A filter is then applied to the model so that only fractures that intersect the $2 \mathrm{D}$ plane and have a dip direction within $20^{\circ}$ of the mean dip direction of the critical set are retained. The filtered fractures traced on the plane are used for rock mass bridge analysis, as described in the next section. In the case study discussed, the process is repeated for 100 DFN model realisations for each scenario tested. 
1. SET UP 3D BOX AND
DEFINE 2D TRACE PLANE.

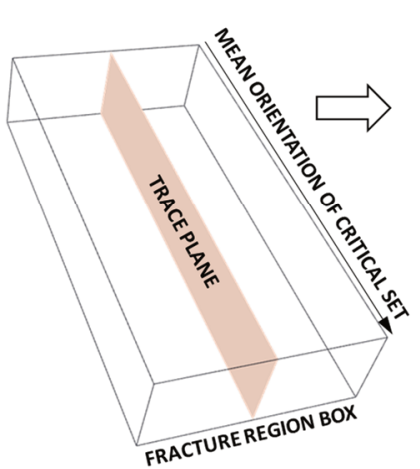

2. GENERATE FRACTURE NETWORK IN 3D BOX.
3. FILTER FRACTURES WITHIN $\pm 20^{\circ}$ OF MEAN DIP DIRECTION OF CRITICAL SET.
4. TRACE FILTERED FRACTURES ONTO PLANE FOR USE IN ROCK MASS BRIDGE ANALYSIS.
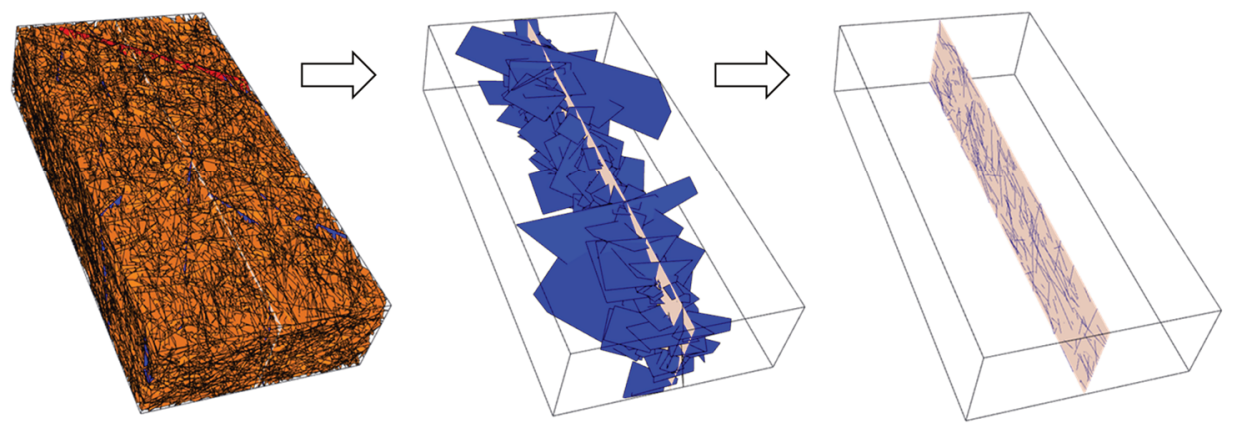

Figure 3 Workflow used to develop and filter DFN models for rock mass bridge characterisation

\subsubsection{Rock mass bridge percentage calculation}

The calculation of rock mass bridge percentage uses the method of Dershowitz et al. (2017). This is a rule-based approach that seeks to identify the most efficient pathway (i.e. minimised objective function) through a 2D section taken from a 3D DFN model, with consideration of some user-defined restrictions on the geometry of the path. This rock mass bridge approach has been verified against more complex geomechanical simulations, with the results showing good agreement (Rogers et al. 2018b).

For each of the 100 trace planes generated from the DFN realisations, the rock mass bridge percentage is calculated (Figure 4a) with the distribution of the 100 simulations (Figure 4b). The design rock mass bridge percentage is defined as the mean minus one standard deviation of the distribution and is used to calculate composite strength parameters for the sliding surfaces.
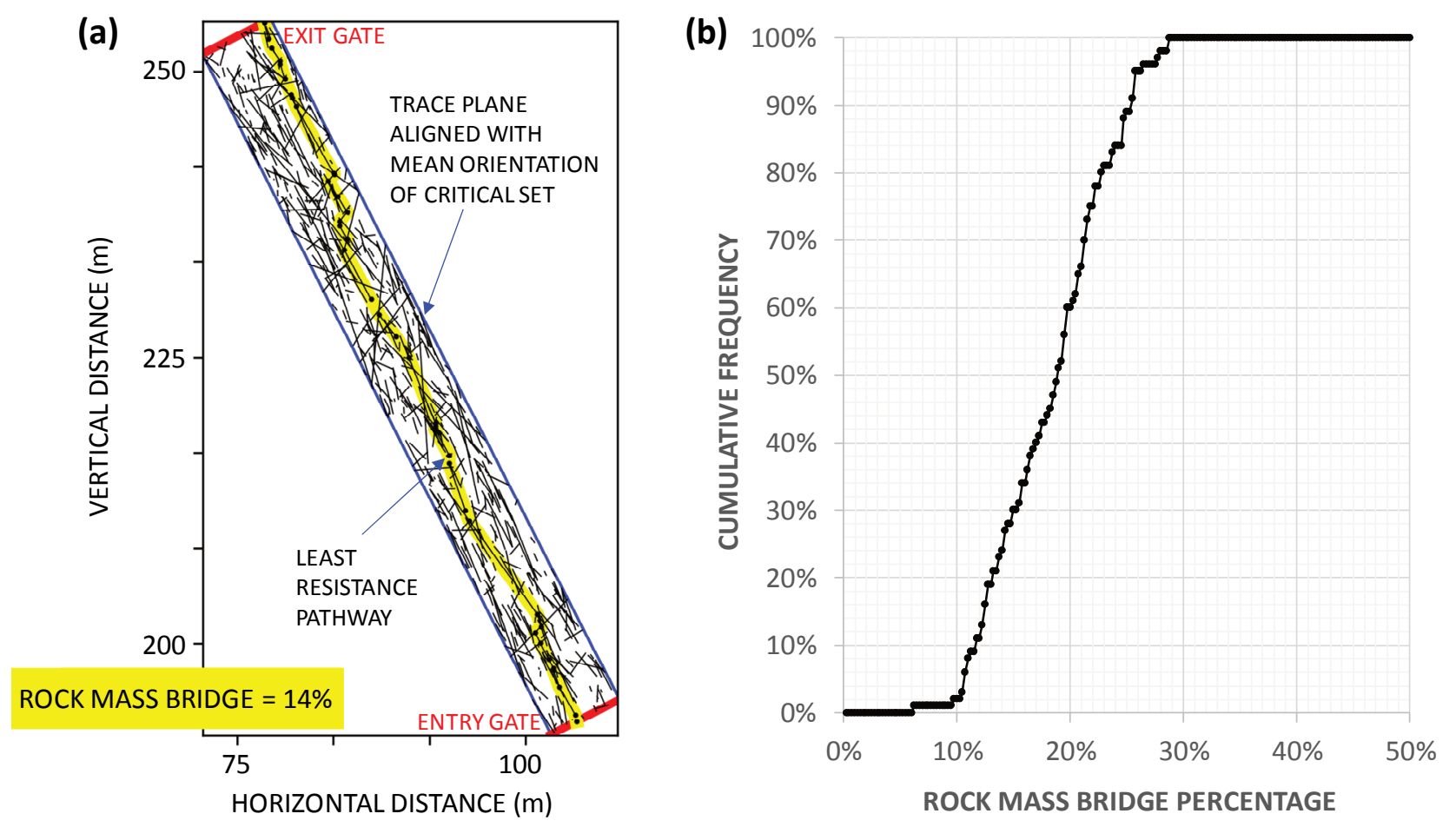

Figure 4 (a) Trace plane showing least resistance pathway identified by rock mass bridge algorithm for one DFN realisation; and (b) statistical distribution of rock mass bridge percentage developed from analysis of 100 DFN realisations 


\subsubsection{Composite strength definition}

Rock mass bridge percentage is a measurement of the length of rock mass bridging over the length of the failure path along a plane aligned normal to the mean orientation of a structural set. The rock mass bridge percentage is incorporated into kinematic stability assessments by calculating composite frictional and cohesive strengths for the sliding surfaces, which combine discontinuity and rock mass strengths. The composite cohesion, $C$, and friction angle, $\phi$, are defined below (after Jennings 1972):

$$
\begin{gathered}
C=(\% R B) \times C_{R M}+(1-\% R B) \times C_{D} \\
\phi=\tan ^{-1}\left[(\% R B) \times \tan \left(\phi_{R M}\right)+(1-\% R B) \times \tan \left(\phi_{D}\right)\right]
\end{gathered}
$$

where $\% R B$ is the rock mass bridge percentage and the $R M, D$ subscripts distinguish between rock mass and discontinuity contributions to the shear strength.

Rock mass strengths are determined from analysis of intact rock strength laboratory test results and geotechnical core logging data. Discontinuity strengths are determined from analysis of direct shear data.

\subsubsection{Statistical kinematic analysis}

Statistical kinematic stability analyses are carried out to assess the potential for inter-ramp scale planar instability to develop along persistent, unfavourably oriented structures. To account for the impact of rock mass bridging at the inter-ramp scale, the composite strength parameters calculated using Equations 1 and 2 are used to represent a combination of rock mass strength and discontinuity strength on the sliding surfaces. The assessment is conducted using RocPlane ${ }^{T M}$ (RocScience Inc. 2019a). This program provides several tools for applying probabilistic kinematic analysis methods to slope design, which are based on the approaches described by Miller (1983), Miller et al. (2000), and Carvalho (2002).

The structural dataset considered in the planar analysis includes only fractures with a dip direction within $\pm 20^{\circ}$ of the normal to the slope. The filtered data are used to develop a simulated probability distribution for the dip of the structures by using the Latin Hypercube random sampling method (Iman et al. 1980) on 10,000 trials. The Factor of Safety (FOS) with respect to sliding is calculated for each of the structures that could form kinematically admissible blocks at the specified IRA. The FOS results are used to calculate the probability of failure (i.e. the number of unstable blocks divided by the total number of realisations) for a specified IRA. For the case study, the number of blocks with FOS less than 1.3 rather than the number of unstable blocks (i.e. FOS less than 1.0) is used in the probability calculation. The results for IRAs ranging from $35^{\circ}$ to $70^{\circ}$ are presented in Figure 5.

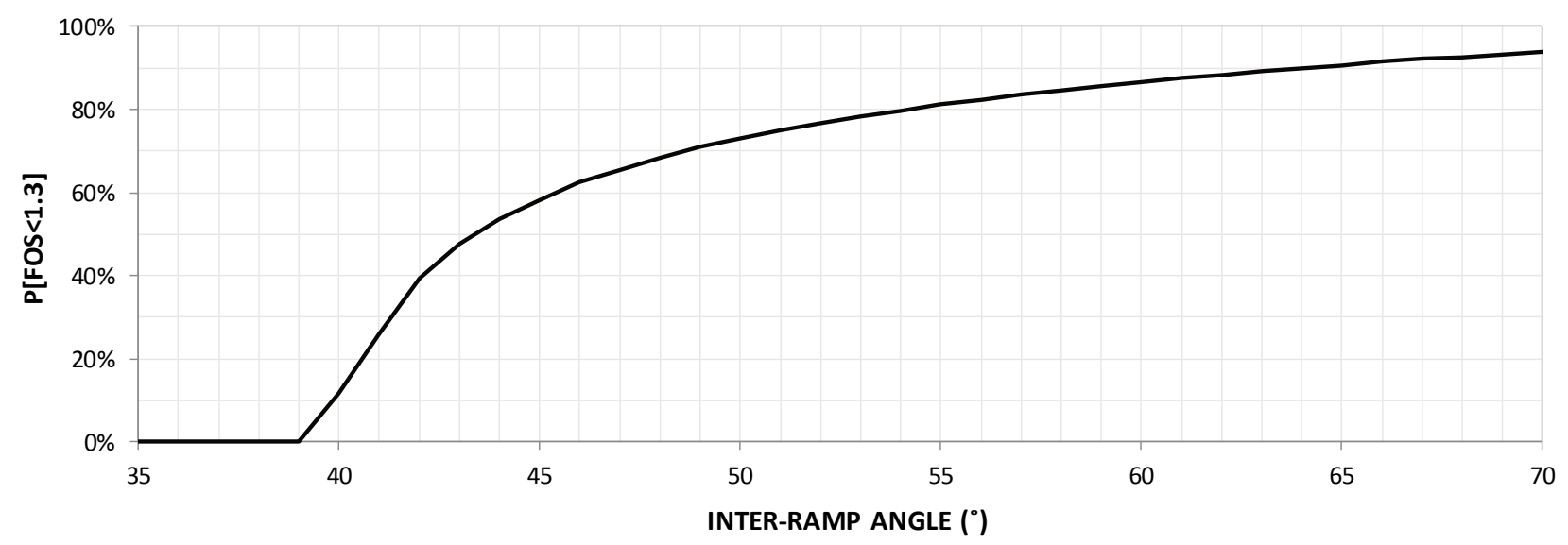

Figure 5 Results of probabilistic kinematic analysis for a range of IRAs

\subsubsection{Inter-ramp angle selection}

Design acceptance criteria for open pit slopes typically consider the scale of the slope and the consequences of failure (Read \& Stacey 2009). In this case study, the inter-ramp design acceptance criterion is defined as a 
maximum of $10 \%$ probability of FOS less than 1.3 with respect to block sliding. This is more conservative than acceptance criteria typically selected for inter-ramp slopes but is considered appropriate for the current discussion. Based on the defined acceptance criterion and the results of the probabilistic kinematic analysis (Figure 5), a design IRA of $40^{\circ}$ would be chosen.

For comparison purposes, an additional kinematic analysis was carried out to assess the impact of excluding rock mass bridges (i.e. discontinuity strengths were used without factoring in rock mass strength). The results indicate that, to meet the design acceptance criterion, an IRA of $37^{\circ}$ or shallower is required. Therefore, in the case study, the use of DFN-based rock mass bridge characterisation to define composite shear strengths results in a design IRA that is $3^{\circ}$ steeper than that achieved using a conventional kinematic assessment.

\subsection{Composite DFN-LE analysis}

Conventional kinematic analysis is used to establish the stability of relatively simple, bench-scale wedges that are daylighted by a slope (Figure 6a). However, at the inter-ramp scale, stability analyses require assessment of blocks with more complex geometries and shapes, that extend hundreds of feet over several benches, and whose stability is controlled by a combination of rock mass strength and discontinuity strength (Figure 6b). Therefore, a simple kinematic evaluation can be viewed as an extreme and perhaps unjustified simplification. To address this, an alternative approach has been developed that combines the 3D complex block identification process of DFN modelling and the stability assessment power of a 3D stress-based LE tool. This approach can be applied independently to small regions of the pit wall to assess unique structural domains, termed a sector-scale analysis, or to full pit-scale models. In sector-scale models, the stochastic nature of the DFN model means that complex blocks can be identified in many different realisations of the DFN over a range of possible slope angles and orientations and their stability evaluated. In pit-scale models, the stochastic realisations are generated over the extent of the pit, which itself is decomposed into separate structural regions.

(a) Simple kinematic wedge

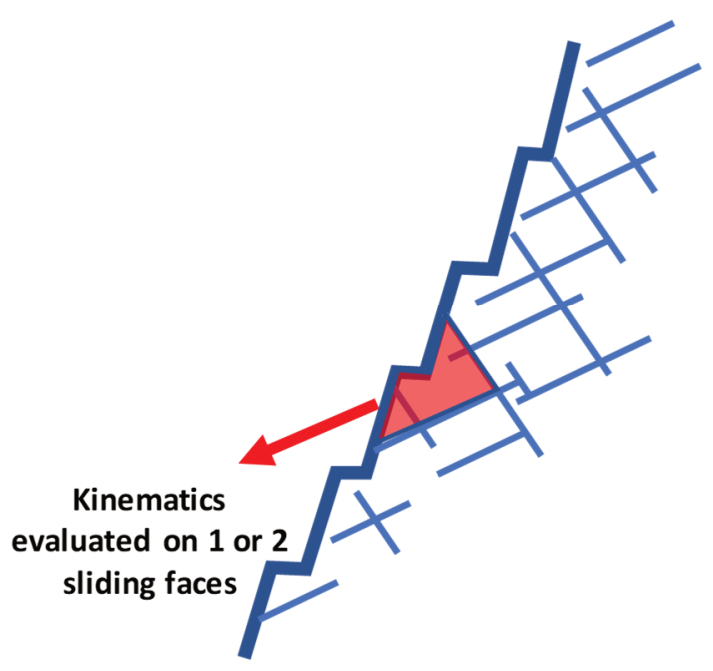

(b) More complex locked in wedge

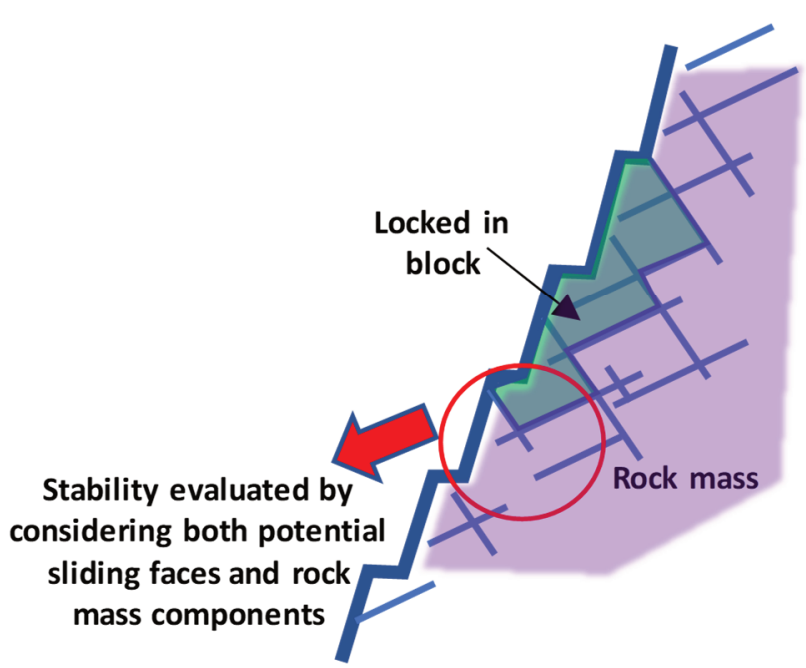

Figure 6 (a) Simple bench-scale wedges that can be assessed through traditional kinematic analysis; and (b) More complex inter-ramp scale blocks

\subsubsection{Sector-scale DFN construction}

When considering sector-scale analysis for inter-ramp designs, analysis should be at a scale large enough to evaluate the possibility of large multi-bench failures, given a combination of large structures and slope configuration. For each design sector, a DFN model can be developed that contains stochastic features at a scale less than that of the mapped major structures. Cell mapping and borehole logging typically show that the intensity of faulting is greater than that explicitly mapped or wireframed, and therefore, it is necessary to stochastically generate these smaller features based upon available site investigation data. 
Depending on the nature of the geology, these sector-scale models can have constant properties (e.g. each fault set has determined stochastic definition of orientation, size, and intensity) or could be more geologically controlled. For example, at Bingham Canyon, intrusion of monzonite has led to deformation and curving of the sediment units and the faults along their contacts. Typical controls on the key geometric properties of the stochastic faults are shown in Table 1. Some examples of the data used to develop DFN input properties are shown in Figure 7.

Table $1 \quad$ Key discrete fracture network properties and their constraints

\begin{tabular}{lll}
\hline Fault geometric parameter & Typically constrained by & Typical distribution \\
\hline Orientation & $\begin{array}{l}\text { Mapping orientation data, } \\
\text { televiewer data, correlation to } \\
\text { geology (e.g. bedding orientation) } \\
\text { Size }\end{array}$ & $\begin{array}{l}\text { Usually Fisher distributions or } \\
\text { bootstrapped from raw data }\end{array}$ \\
& $\begin{array}{l}\text { Mapping data, photogrammetry, } \\
\text { scaling laws that integrate all size } \\
\text { measurements }\end{array}$ & $\begin{array}{l}\text { Skewed distributions (e.g. power } \\
\text { laws, log normal, exponential) }\end{array}$ \\
Intensity & $\begin{array}{l}\text { Typically defined from borehole } \\
\text { data, adjusted to reflect minimum } \\
\text { modelled size different to logged } \\
\text { core }\end{array}$ & $\begin{array}{l}\text { Usually constant for a design sector } \\
\text { but may show local variation by } \\
\text { geology (e.g. distance from a bed, } \\
\text { distance from a fault) }\end{array}$ \\
\hline
\end{tabular}

For the Bingham Canyon study, the slope for each design sector has an overall height of approximately $200 \mathrm{~m}$, a width of approximately $200 \mathrm{~m}$, and a constant design bench face angle of $68^{\circ}$. For each sector (ex situ) model, at least 30 different slope configurations are tested, varying the IRA from $32^{\circ}$ to $50^{\circ}$ and using three different slope azimuths.

Multiple realisations of stochastic features are generated with the DFN model. For each realisation of the DFN model and slope configuration, FracMan identifies all enclosed blocks (multi-faceted wedges) that are enclosed by discontinuities and/or the pit surface. FracMan has the internal capability to evaluate the stability of these blocks (Figure 6a) using LE or force balance approaches implemented in other design tools such as UnWedge ${ }^{\mathrm{TM}}$ (RocScience Inc. 2019b), but blocks that do not daylight at the pit surface (Figure 6b) are identified to be kinematically locked in and therefore excluded from analysis. To overcome this limitation, a unique stress-based LE tool, capable of assessing blocks whose stability is controlled by both rock mass strength and kinematics, has been developed by Golder. The workflow is described in the next section. 
(a)

Trace length (ft)

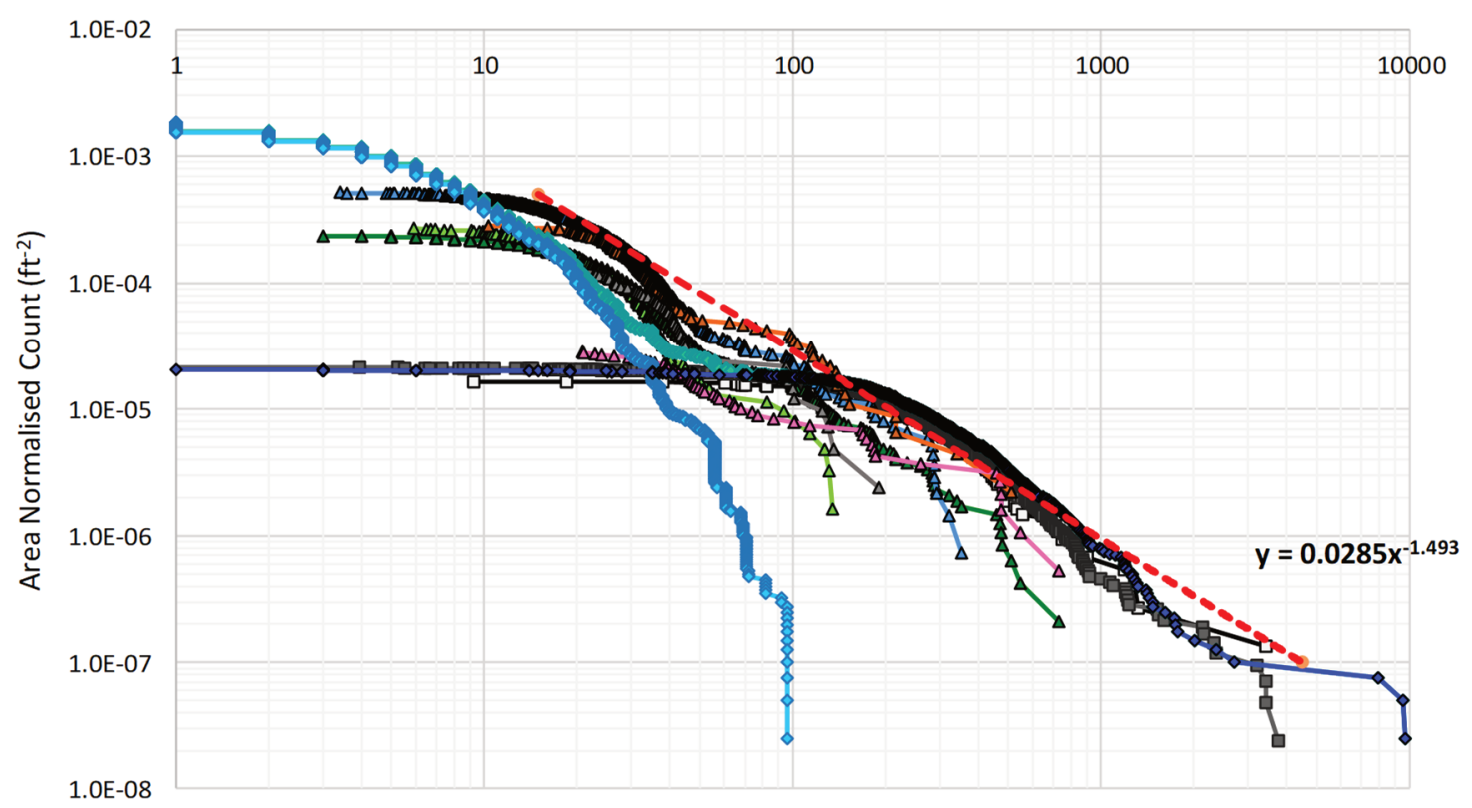

(b1)

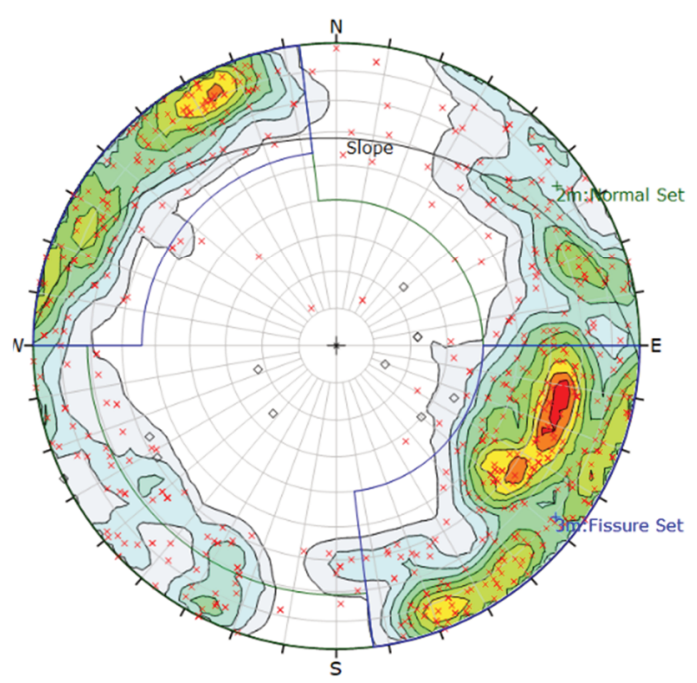

(b2)

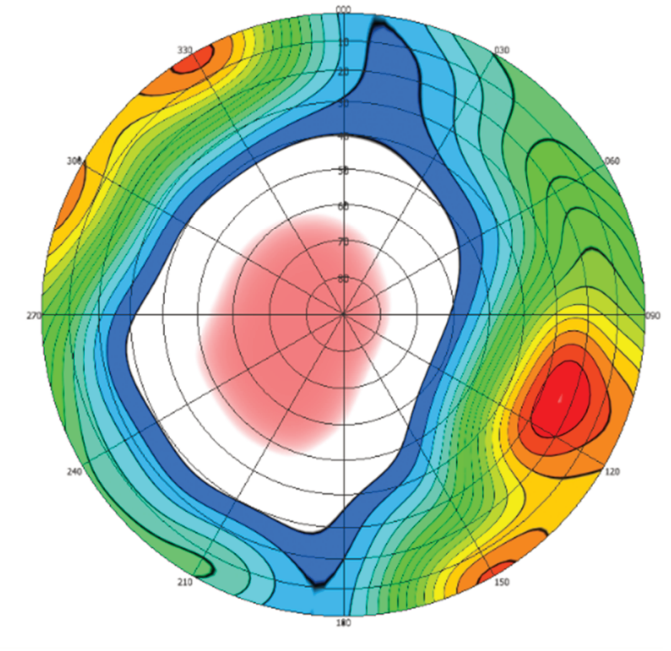

Figure 7 Examples of input data for DFN models: (a) Compilation of mapping length data from a range of scales including bench mapping, photogrammetry scans, and major structure wireframes that all conform to the same power law trend; and (b) Comparison between actual mapped orientation data (b1) and simulated orientation patterns (b2)

\subsubsection{DFN-LE workflow}

The DFN-LE workflow is presented in Figure 8. In situ or ex situ DFN models are first developed using relevant structural inputs as discussed above. Multiple realisations of stochastic features are generated to identify a large number of blocks to use in a probabilistic assessment. The FOS of blocks pertinent to the scale of the investigation are then evaluated using the unique LE tool, as well as composite blocks formed by assembly of one or more adjacent blocks (i.e. blocks that share a common face). The FOS results can be used to calculate the probability of failure for a specific IRA using a similar approach to that used in the simple kinematic analysis. 


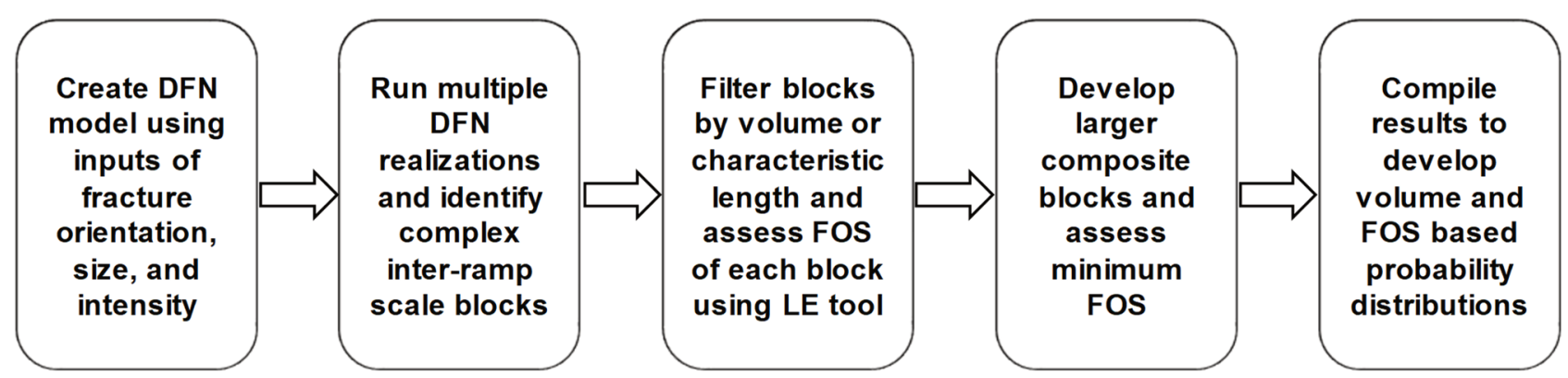

Figure 8 Workflow for inter-ramp stability analysis using composite DFN-LE approach

\subsubsection{Custom LE-based algorithm}

The stress-based LE approach used to determine the FOS for a sliding block is very similar to the calculation methods embedded in FracMan and UnWedge. It differs, however, in how it identifies the failure surface and reports the final FOS. Complex and irregular polyhedral shapes are identified by FracMan but may be kinematically restricted from sliding by a stabilising rock wedge at the toe of the block or by an irregular geometry along its basal sliding plane. Therefore, a slip surface identification algorithm was developed to identify a fully daylighted slip surface honouring, within an acceptable tolerance, the complex nature of the slip surface formed by the intersecting discontinuities. The algorithm is based upon developing an optimised lower convex hull for the complex geometries, extended (daylighted) to form a continuous basal sliding surface. Regions of failure through rock mass or along discontinuities are differentiated along the failure surface to permit a FOS assessment based upon their independent strength properties (i.e. no composite rock mass bridge strengths are necessary). Lawrence et al. (2020) outline the slip surface identification methodology in detail.

The FOS along the slip surface, defined as the resisting to driving force ratio, is calculated as:

$$
\text { FOS }=\frac{\text { Resisting Force }}{\text { Driving Force }}=\frac{\sum\left(c_{i}+\sigma_{n_{i}} \tan \varphi\right) A_{i}}{\sum \tau_{i} A_{i}}
$$

where $c$ and $\varphi$ are the cohesion and friction angle describing the shear strength of the rock mass or discontinuity, $\sigma_{\mathrm{n}}$ and $\tau$ are the normal and shear stresses acting at a point on the slip surface, and $A$ is the area of the regions of the slip surface.

In the current approach, the slip surface is derived in the form of a uniform triangular mesh, so the strength, stresses, and area are defined on a per triangle basis. Mohr-Coulomb strengths are used for discontinuities and equivalent (instantaneous) Mohr-Coulomb strengths are used for Hoek-Brown characterised rock mass. The full stress tensor from 3D finite element or finite difference packages or simple gravitational stresses can be considered, along with 3D pore pressure distributions. These key steps have been implemented in ${\mathrm{C}++^{\mathrm{TM}}}^{\mathrm{M}}$ to optimise performance (speed); slip surface identification and FOS evaluation can be performed on complex geometries in milliseconds. Pre- and post-processing steps to develop configuration files and assemble data metrics of the results are performed using Python ${ }^{\top \mathrm{M}}$ scripts. The workflow, from FracMan model construction and block identification, to slip surface identification and FOS assessment, is completely automated.

\subsubsection{Statistical sector analysis}

For a single design sector, statistical kinematic stability analyses can be performed using this new workflow to assess the potential for inter-ramp scale instability to develop. For Bingham Canyon, at least 100 realisations are considered using the sector-scale models in FracMan for at least 30 slopes (IRA from $32^{\circ}$ to $50^{\circ}$, and design azimuth $\pm 10^{\circ}$ ), each of which identifies hundreds to thousands of blocks depending on the structural properties of the sector (Figure 9). The number and size of blocks formed are a function of the statistically generated DFN model for a given realisation. Statistics are generated based on 100 realisations. 

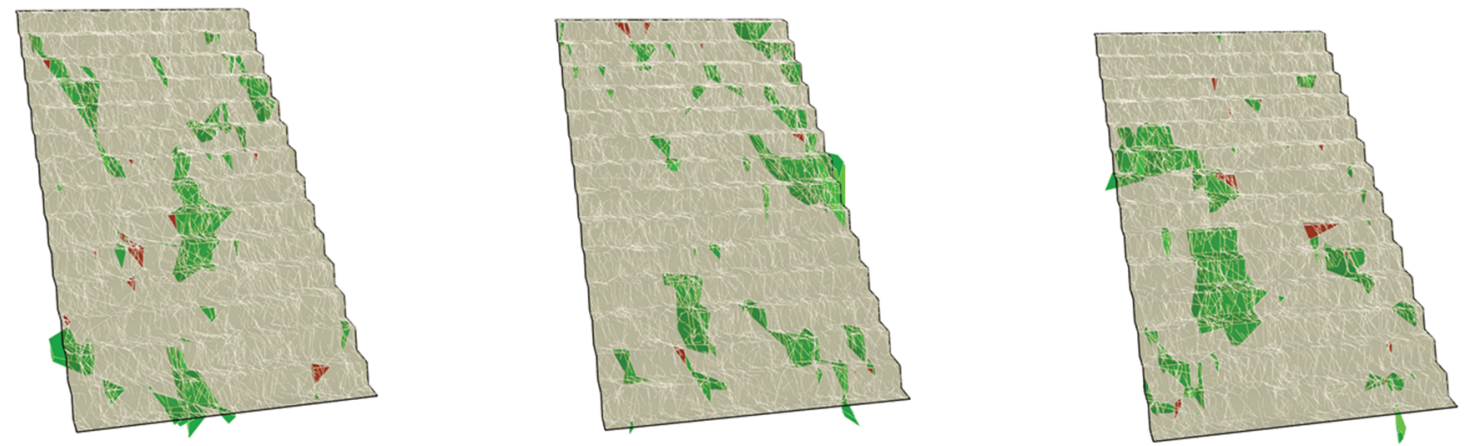

Figure 9 Block formation in three of the minimum 100 realisations of a sector-scale DFN FracMan model

The minimum FOS for each block and/or composite blocks (considering combination of neighbouring blocks within a realisation) is aggregated to develop a simulated distribution for the probability of failure (i.e. the number, or mass, of unstable blocks divided by the total number of realisations) for the specified IRA (Figure 10). At the $10 \%$ probability of FOS $<1.3$ defined in the kinematic analysis (Section 3.1.5), an IRA of approximately $40^{\circ}$ is derived from Figure 10 . Unstable mass metrics can also be developed based upon the sector-scale approach.

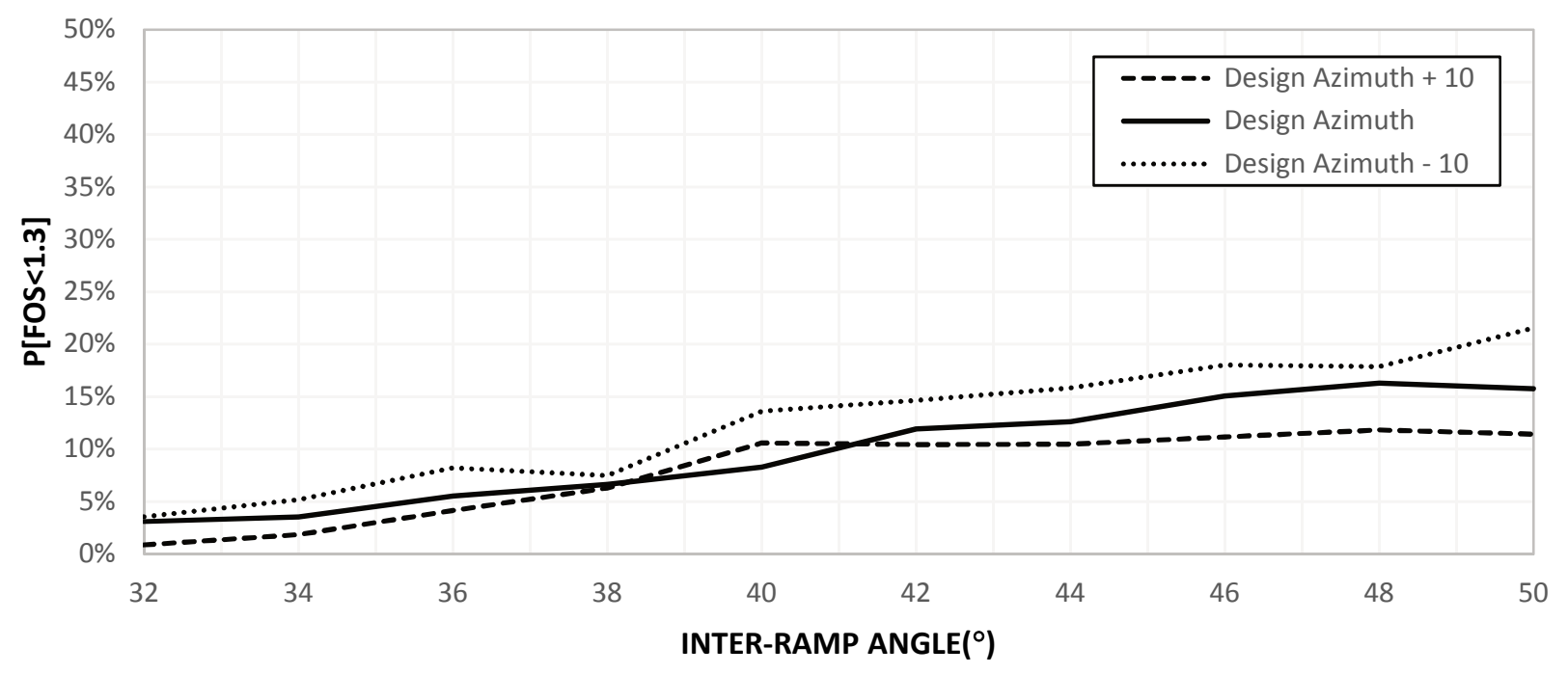

Figure 10 Probability of block having FOS $<1.3$ as a function of IRA for three different azimuths

Over the course of the case study, over 500,000 blocks were identified by FracMan realisations, and tens of millions of composite blocks were evaluated using the unique LE tool. The sector-scale results can be collated to provide IRA design recommendations per design sector of the pit.

\subsubsection{Pit-scale DFN construction}

Sector-scale models are aimed at identifying critical combinations of smaller scale faults and particular slope design configurations. However, this does not explore the impact of key major structures on block formation and stability. To account for this, wall-scale DFN models can be developed that capture both the smaller scale faults (defined on a sector-by-sector basis) and larger deterministic faults. A workflow for developing large-scale DFN slope models is provided by Rogers et al. (2009).

There are two deterministic fault classes that need to be considered, namely major fault wireframes for direct inclusion within the slope-scale model and also mapped larger structures that exist within databases of features but not as wireframed surfaces in the geological model. Trace-map faults can be converted into 3D objects by taking the mapped fault trace and generating a fault around it that honours the location and 
orientation of the mapped fault whilst stochastically sampling the size of the structure (e.g. Rogers et al. 2016). An example of a wall-scale model from Bingham Canyon is shown in Figure 11.

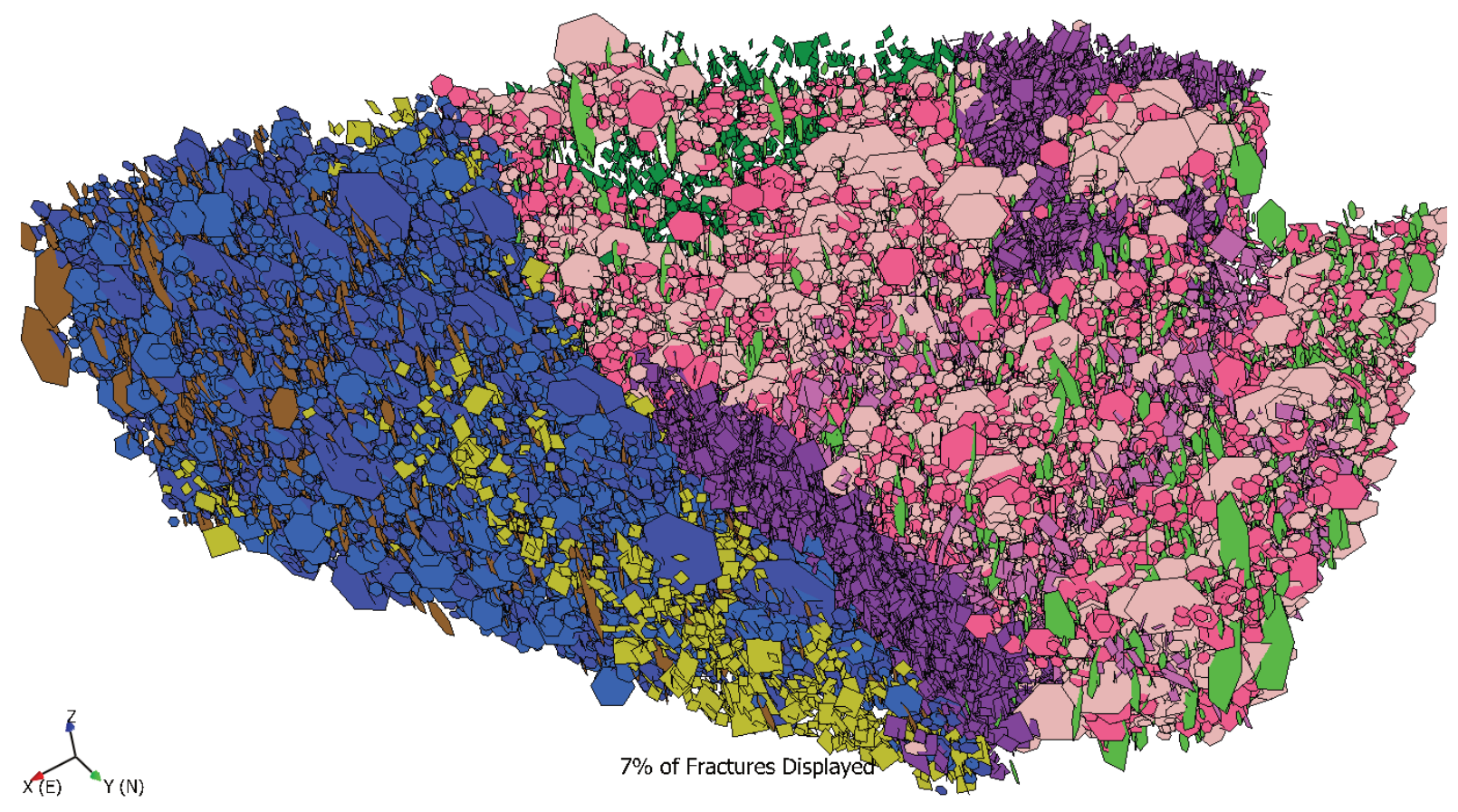

Figure 11 Example of pit-scale DFN model

To help identify areas of the slope that result in higher probability of block formation, the results of multiple realisations are accumulated together by mapping all of the formed blocks, regardless of FOS, in a 3D grid and then colouring that grid by the number of blocks present at that location. This grid is then displayed as a heat map, exhibited in Figure 12, with areas that show more common block formation seen as red (hot) colours and areas where there is no specific driver seen as blue (cold) colours.

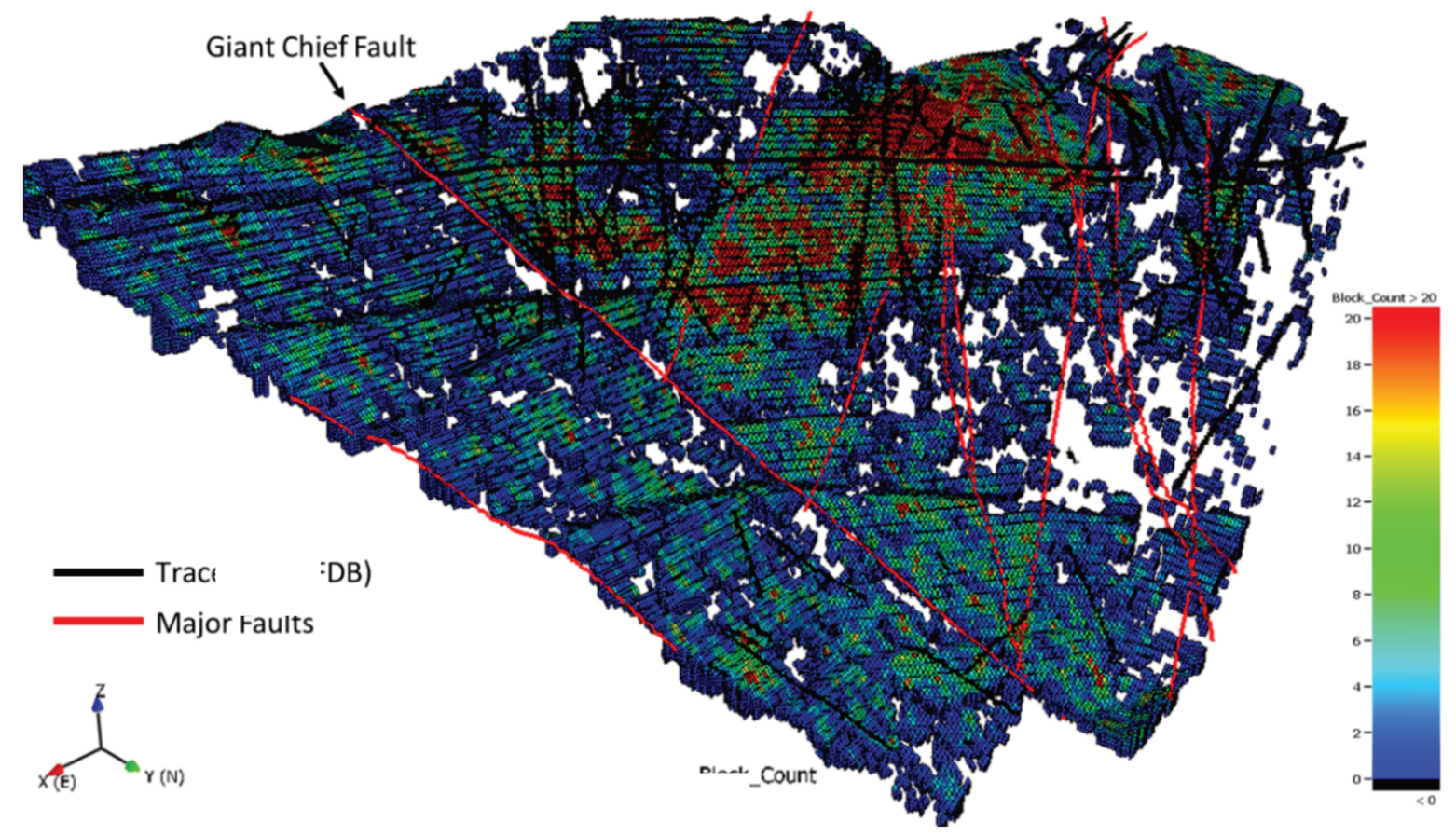

Figure 12 Heat map of block formation, with high probability of block formation shown in red and low probability shown in blue 
Finally, the stability of these complex blocks over the extent of the pit is evaluated using the same processes outlined in the sector-scale analysis. The generation of DFN models and identification of the complex blocks is more computationally intensive using the larger pit-scale model, but the LE component of the new DFN-LE approach is unchanged. Statistics are still collated, though now referencing the true region of the pit instead. Heat maps, similar to the example presented in Figure 12, are developed to differentiate regions of the pit where there is a higher probability of inter-ramp stability. These heat maps and unstable mass estimates are then used to inform risk and financial mitigation efforts.

\section{Conclusion}

Two inter-ramp design approaches have been described in this paper that use DFN-based methods to address some of the limitations of existing approaches in assessing instability mechanisms involving both rock mass and structural failure. The two methods presented capture complex structural networks and are capable of rapidly performing probabilistic analyses of composite failure mechanisms comprising both structural and rock mass components.

The first approach integrates DFN-based rock mass bridge characterisation with probabilistic kinematic methods available in widely used commercial software. The relative proportions of rock mass and discontinuities on potential failure surfaces are determined through multiple DFN realisations, and those results are then used to define the composite strength of the surfaces considered in planar or wedge stability analyses.

The second approach combines DFN modelling and a 3D stress-based LE tool developed by Golder. The DFN model is used to identify large multi-bench 3D complex blocks generated from multiple stochastic realisations over a range of IRAs and slope azimuths in a sector-scale analysis, or over a larger extent in a pit-scale analysis. The LE tool is used to rapidly assess the stability of the identified blocks. This composite DFN-LE approach permits probabilistic analysis of complex inter-ramp scale blocks whose stability is controlled by a combination of discontinuity and rock mass strength.

To gain confidence in the second, novel but more flexible approach, both methods have been used together to aid in developing inter-ramp slope angle recommendations at the Bingham Canyon mine. Future studies will consider back-analysis of slope instabilities to provide further validation of the approach. The workflows presented in this paper have contributed significantly to advancing the application of DFN models to interramp slope design, and more generally provide practical tools for efficiently evaluating complex failure mechanisms and informing the choice of design IRAs.

\section{Acknowledgement}

The authors acknowledge Rio Tinto, Rio Tinto Kennecott, and their employees for their support, collaboration, and permission to publish the information in this document.

\section{References}

Carvalho, JL 2002, 'Slope stability analysis for open pits', RocScience Newsletter, viewed 18 September 2019, https://www.rocscience.com/documents/pdfs/rocnews/april2002/GolderArticle.pdf

Carvalho, JL, Lawrence, KP, Moffitt, KM \& Yetisir, M 2019, 'Behaviour and realm of application of ubiquitous joint constitutive models - facts and limitations', Proceedings of the 53rd US Rock Mechanics Symposium, American Rock Mechanics Association.

Chiles, J, Wackernagel, H, Beucher, H, Lantuejoul, C \& Elion, P 2008, 'Estimating fracture density from a linear or aerial survey', Proceedings of the VII International Geostatistics Congress, Santiago, pp. 535-544.

Cladouhos, TT \& Marrett, R 1996, 'Are fault growth and linkage models consistent with power-law distributions of fault lengths?', Journal of Structural Geology, vol. 18, no. 2, pp. 281-293.

Dershowitz, WS \& Herda, HH 1992, 'Interpretation of fracture spacing and intensity', Proceedings of the 33rd US Rock Mechanics Symposium, American Rock Mechanics Association.

Dershowitz, WS, Finnila, A, Rogers, S, Hamdi, P \& Moffitt, KM 2017, 'Step path rock bridge percentage for analysis of slope stability', Proceedings of the 51st US Rock Mechanics Symposium, American Rock Mechanics Association.

Efron, B 1979, 'Bootstrap methods: another look at the jackknife', The Annals of Statistics, vol. 7, no. 1, pp. 1-26. 
Golder Associates Inc. 2019, FracMan, version 7.8, computer software, Golder Associates Inc, Redmond, https://www.golder.com/fracman/

Iman, RL, Davenport, JM \& Zeigler, DK 1980, Latin Hypercube Sampling (a program user's guide), Technical Report SAND 79-1473, Sandia Laboratories, Albuquerque.

Jennings, JE 1972, 'An approach to the stability of rock slopes based on the theory of limiting equilibrium with a material exhibiting anisotropic shear strength', Proceedings of the ASCE 13th US Symposium on Rock Mechanics, American Society of Civil Engineers, pp. 269-302.

Lawrence, KP, Nelson, M, Yetisir, M \& Matlashewski, P 2020, 'Kinematic assessment of composite failure mechanisms in pit slopes: a novel slip surface identification algorithm for DFN models', Proceedings of the 54th US Rock Mechanics Symposium, American Rock Mechanics Association.

Merrien-Soukatchoff, V, Korini, T \& Thoraval, A 2012, 'Use of an integrated discrete fracture network code for stochastic stability analyses of fractured rock masses', Rock Mechanics and Rock Engineering, vol. 45, no. 2, pp. 159-181.

Miller, SM 1983, 'Probabilistic analysis of bench stability for the use in designing open pit mines', Proceedings of the 24th US Rock Mechanics Symposium, American Rock Mechanics Association, pp. 621-629.

Miller, SM, Girard, JM \& McHugh, EL 2000, 'Computer modeling of catch benches to mitigate rockfall hazards in open pit mines', Proceedings of the 4th North American Rock Mechanics Symposium, American Rock Mechanics Association, pp. 539-545.

Read, J \& Stacey, P 2009, Guidelines for Open Pit Slope Design, CSIRO Publishing, Collingwood.

RocScience Inc. 2019a, RocPlane, version 3.0, computer software, RocScience Inc., Toronto, https://www.rocscience.com/software/ rocplane

RocScience Inc. 2019b, UnWedge, version 4.0, computer software, RocScience Inc., Toronto, https://www.rocscience.com/software/ unwedge

Rogers, S, Moffitt, KM \& Kennard, D 2006, 'Probabilistic tunnel and slope block stability using realistic fracture network models', Proceedings of the 41st US Rock Mechanics Symposium, American Rock Mechanics Association.

Rogers, S, D'Ambra, S, Dershowitz, WS \& Turnbull, R 2018a, 'Probabilistic bench scale slope designs based upon realistic discrete fracture network models', Proceedings of the 2018 International Symposium on Slope Stability in Open Pit Mining and Civil Engineering, BCO Congresos, Barcelona.

Rogers, SF, Elmo, D, Beddoes, R \& Dershowitz, B 2009, 'Mine scale DFN modelling and rapid upscaling in geomechanical simulations of large open pits', in JR Read (ed.), Proceedings of the International Symposium on Rock Slope Stability in Open Pit Mining and Civil Engineering, University de los Andes, Santiago, CD-ROM only.

Rogers, S, Elmo, D, Webb, G \& Guajardo, C 2016, 'DFN modelling of major structural instabilities in a large open pit for end of life planning purpose', Proceedings of the 50th US Rock Mechanics Symposium, American Rock Mechanics Association.

Rogers, S, Hamdi, P, Moffitt, KM \& Dershowitz, WS 2018b, 'DFN based analysis of step path failure pathways for improved slope stability analysis', Proceedings of the 2018 International Symposium on Slope Stability in Open Pit Mining and Civil Engineering, BCO Congresos, Barcelona. 